\title{
Prediction of Malaysian Exchange Rate Using Microstructure Fundamental and Commodities Prices: A Machine Learning Method
}

\author{
Shamaila Butt, Suresh Ramakrishnan, Muhammad Ali Chohan, Suresh Kumar Punshi
}

\begin{abstract}
The key objective of this research is to investigate the short run dynamics of the exchange rate using commodity prices and microstructure market variables for developing economies, Malaysia. The analysis of the literature revealed different school of thought where one claims the strong correlation among the variables while other significantly reject the relationship. There is mixed results that support and reject the accurate forecasting of the exchange rate through different determinants. Therefore, in this study the machine learning approach is applied to perform the extensive experiments and investigate the relationship between the commodity prices, bid-ask spread and exchange rate. Three techniques were selected from the machine learning i.e. artificial neural network, RandomForest and support vector machine. The experimental results revealed that randomforest perform better than SVM and ANN, both in the performance and accuracy. Thus, the exchange rate can be predicted will reasonable accuracy using the commodity prices in the combination of the bid-ask spread. Thus, the policy maker can be utilized these results for strategies development, corporate planning and building investment plan.
\end{abstract} spread; RandomForest; Support Vector Machine; Artificial Neural Network.

\section{INTRODUCTION}

The objective of this article is to capture the short run dynamics of Malaysian Ringgit. Since the development of the concept of "Meese and Rogoff puzzle" introduced by Meese and Rogoff [1], it has been well known that exchange rates are very difficult to predict using economic models. These economic models are providing the reasonable achievements for long-run forecasting. However, its contribution on the short-run forecasting is minimum. Particularly, the random walk model, using the simplest approach can perform better exchange rate prediction than economic and econometrics model. The toughest benchmark is the random walk. The recent literature has identified the microstructure fundamental and commodities prices that claim to forecast exchange rate.

Revised Manuscript Received on September 22, 2019.

Shamaila Butt, Azman Hashim International Business School, Universiti Teknologi Malaysia, 81030 Johor Bahru, Johor, Malaysia

Department of Management Sciences, Universiti of Wah, Wah Cantt, Pakistan, shamaila.butt87@gmail.com

Suresh Ramakrishnan, Azman Hashim International Business School, Universiti Teknologi Malaysia, 81030 Johor Bahru, Johor, Malaysia Universiti Teknologi Malaysia, 81030 Johor Bahru, Johor, Malaysia
Index Terms: Exchange rate; Commodity Price; Bid-Ask

Muhammad Ali Chohan, Azman Hashim International Business School,

The debate that exchange rates are predictable or unpredictable is an open question throughout the literature [2]. The unsolved mystery led to the generation of high frequency data and enabled the researchers to study the in-depth effects of the exchange rate dynamics. This brought a new theoretical improvement in the determination of the exchange rate. Evans and Lyons [3] introduced the concept by incorporating the microstructure information. This information is also known as private information. The introduction of the microstructure approaches brought dramatic developments in short run horizon and has a significant impact on the exchange rate dynamics. The literature showed that the microstructure approaches to exchange rates have achieved substantial improvements due to the availability of high quality and high frequency data [4, 5]. Moreover, besides the microstructure fundamentals, the commodities prices have also considered as an important determinant of the exchange rate in export oriented economies. The literature provides robust empirical evidences to show the relationship between the exchange rate and commodity prices in the developed economies [6-9].

Moreover, the econometrics techniques also played vital role in the prediction of exchange rate. The extensive literature showed that economic and econometric models are linearly predictable and these models produced results if the data have linear patterns. However, these techniques show limited performance with the nonlinear pattern. The issue of the non-linear patterns in the exchange rate's prediction induced the researcher to use the machine learning techniques. Machine learning methodologies gained significant importance due to their ability of modeling the nonlinear systems with high forecasting accuracy. Overall, the forecasting ability of the machine learning methodology in time series forecasting has attracted many researchers in the relevant literature. The literature showed that the use of machine learning technique have remarkable improvements to forecast the movements in exchange rates [10-12].

The study of exchange rate in less developed countries (LDCs) and emerging economies is restrictive in comparison with the developed economies. However, the forecasting of the exchange rate brings more complexities when it comes to the exchange rate prediction of the developing countries. In general, all developing economies have a high degree of similarity in their economic structure, geographical location, and stages of development. 
But each economy has taken different measures to respond to the economic collapse. Therefore, every country has their own specific conditions to deals with the exchange rate dynamics. In the Asian countries, the Malaysia, is considered one of the major developing countries that greatly relies on external trade and affects by global economic condition. The complex nature of exchange rate determination increased the interest of researchers to re-explore the Malaysian experience as a small and export oriented open developing economy in Southeast Asia.

The objective of this article is to investigate both microstructure and commodities prices as a new proposed exchange rate predictor for short run and assess their ability to forecast Malaysian Ringgit. The key goal is to answer the questions: Are Malaysian Ringgit predictable through microstructure fundamental and commodities prices in the short run? And, Do the machine learning technique is effective in forecasting the exchange rate in Malaysia? TO get answer to these questions, the in-depth analysis of the literature is performed which highlights that the prediction of the exchange rate depends on a number of factors. These factors include the choice of predictor, model, forecast horizon, choice of predictor, and forecast evaluation method. Therefore, there are several choices for the researchers to forecast exchange rates [13]. The past studies highlighted that if one model is producing promising results in one country, they may not provide the results with same significance in another country $[14,15]$. It showed the predictive ability is also heavily depending on the choice of the country for a given model and predictor. Thus, the prediction of the exchange rate might provide significantly different results with the different predictors and different country. One of the goal of this research is to highlight the microstructure concept to predict the Malaysian exchange rate. The extensive literature showed that the microstructure studies focused on the developed market. However, conceptual studies on the Malaysian foreign exchange market are often neglected by most researchers. This negligence is probably due to the smallest trading size of the Malaysian market and the ringgit is not being one of active currencies traded in the international market. Moreover, the liquidity aspect of the Malaysian foreign exchange market continues to be a puzzle to the researchers. Therefore, to cover this potential gap, the focus is to highlight the significance of market microstructure Malaysian forex market. Besides the microstructure fundamentals, the commodities prices have also considered a significant factor of the exchange rate. The literature has very little evidences in the support of the commodities prices in developing economies. The commodities prices are the important factors in determining the strength of the predictability. Thus, this article incorporates it with the microstructure fundamental to evaluate the short run impact of predictors on the Malaysian exchange rate. In addition, this research performs an empirical evaluation of the predictors using the most recent machine learning techniques.

This article is targeting a number of different audience who can get benefit from the outcome of this research. The significant contributions of this study are twofold, specifically, empirical contribution, and policy implication.
In terms of the empirical contribution, it fills the gap in the body of knowledge associated with the microstructure fundamental and commodities prices. The past literature mostly focused on the macroeconomic analysis of the exchange rate in the long run. This study focusses the exchange rate prediction in short run. Furthermore, this research contributes in terms of methodological improvements by introducing the machine learning techniques. The machine learning technique provides more accurate results in short run forecasting. The highly accurate forecasting of exchange rate is very important to assess the pros and cons associated with the dynamics of the exchange rate. Therefore, the machine learning technique are used to fill the gap associated with accuracy of the forecasting models. Secondly, from a policy implication point of view, this study is helpful for business community, foreign investors, policy makers, banks, financial institutions, and domestic and international firms. Moreover, it is also beneficial for decision maker to get the future atmosphere of the exchange rate and make informed decision.

The rest of the paper is organized as follow. Section 2 review the literature; Section 3 overviews the research framework, forecasting techniques and evaluation methods; Section 4 provide the empirical evidence through empirical exercise. Section 5 summarized the findings.

\section{LITERATURE REVIEW}

Bid-Ask Spread (spread) is the difference between the selling (ask) and buying (bid) prices. Paukštè and Raudys [16] noted that spread is signified by the best bid and best ask price. The theory of microstructure approach proposes the three main determinants of bid ask spread. The first determinant is known as the cost of dealer services that is analysed by [17]. The cost of dealer services represented that buy and sell orders generally do not reach the market at the same time. Further, the second determinant examined by Bagehot [18] is called cost of adverse selection on bid-ask spreads. The second determinant shows that spread is the compensation for dealers who might lose money in the process of trading with the better informed agents. The cost of holding inventory is a third determinant of bid-ask spreads which derives by [19]. The cost of holding inventory emphasized that spread is the compensation for dealers who provide immediacy and assume risk by holding inventory at the same time.

Furthermore, market risk is the most prominent factor in explaining the changes in bid-ask spreads in the literature. The greater uncertainty widening the spread regarding the spot rate. Thus, risk-averse traders increase the spread to offset the increased risk of losses. Subsequently, some studies have examined that market uncertainty is the most important reason for deviating from conventional interbank bid-ask spread. For Example, Cheung and Wong [20] found that practitioners generally follow the market convention to set their interbank bid-ask spreads, consistent with the empirical clustering of spreads. 
The past studies investigated that bid-ask spreads have significant positive impact on exchange rate. Moreover, liquidity as measured by the bid-ask spread is important in the determination of the foreign exchange rate, especially for low trading currencies [21]. In line with these arguments, a recent study by Katusiime, et al. [22] confirmed the positive association between the bid-ask spread and the exchange rate at short run and long run horizons in Ugandan economy during the period 1995M1 to 2013M3. In Malaysia, there is a lack of analysis on spread. Malaysia is observing a low trading volume in comparison with developed economies. The theoretical foundations expect a large spread in developing economy.

Moreover, commodities prices are considered as an important antecedent of the exchange rate [23]. Crude Oil is a major commodity used as an input into the industrial and production sector and has an effect on the prices of finished products. Oil prices affect the input prices which in turn impact the total costs of production [24]. It has been well documented that there is a strong relationship between exchange rates and oil prices, in particular, for the countries whose economy heavily depends on oil as an importing or exporting product $[6,25]$. In country-specific contexts, Koranchelian [26], and Zalduendo [27] documented a key role of the oil price as a trigger of exchange rate movements. [28] modified the monetary model of exchange rates by adding oil prices and find that oil prices can significantly explain the exchange rates of US dollar against major currencies in some oil export countries. Akram [29] also revealed a negative relationship between oil prices and the value of the Norwegian exchange rate. Hussain, et al. [30]) investigates the relation between oil prices and exchange rate to investigate the oil price and exchange rate in 12 Asian countries, including Malaysia. The results have important monetary, fiscal, inflationary, and trade policy implications for these countries.

Moreover, Palm oil is also considered to be one of the important commodity especially in Malaysia. The increase export of palm oil appreciates the currency. Similarly, the result found by Aprina [31] as the impact of palm oil exports on domestic exchange rate movements. It shows that palm oil export economies get the benefit to upsurge in the prices and a negative relationship between palm oil prices and exchange rate. Also, Shri Dewi, et al. [32] conducted the study on the palm oil fluctuation that effect on the export of the economy. The study discussed the world palm oil prices positive associated with the foreign exchange. Malaysia remained at the top rank regarding the market share for export oriented economy. The value of palm oil exports affects the availability of foreign exchange. In addition, the natural rubber is the main contributor in Malaysian economy.

\section{METHODOLOGY}

\section{A. Data and Sources of Data}

The data sources for the data used in this research includes Malaysia Rubber Export Promotion Council, Bank Negara Malaysia, Department of Statistics Malaysia, and Organization of Petroleum Exporting Countries. After the data collection, the data were analysed for anomalies. This identified a number of records with missing values and accordingly the data were cleansed to avoid the misleading results. Every data source has different period of data available i.e. Exchange rate is available since 1971, Palm oil from 2008, and the rubber data is available since 2005. Therefore, in research we chose to utilize data between January 2008 to December 2017 to get a uniform timestamp for all variables. Next, the for only working days are considered during experiments and all the weekend and public holidays dates were removed from the data. After the extensive pre-processing, we were left with 2335 records for five attributes i.e. four independent and one dependent variable. All variables are numeric. The data sources and variable description is provided in Table 1. Weka 3.9.1 were used for experiments and data analysis. The same platform is used for model evaluation and accuracy.

\section{B. Data Cleansing}

There were some attributes with missing values. All those records were deleted were the exchange rate were not available. For other attributes, the missing values were imputed using Weka. The default missing value filter uses Bin mean to fill the missing values by taking the mean of the adjacent record.

\section{Machine Learning Techniques}

Machine learning techniques are the prominent techniques that gained popularity in the academia due to its significant improvement in building accurate model. The techniques in the machine learning have powerful tools and statistical models that achieved considerable results in almost every field of life, including finance. These significant techniques include Artificial Neural Network (ANN), Support Vector Machine (SVM), and Decision tree (DT).

ANN consist of a number of hidden layers whose number can be decided based on the Eq. 1. There are two other important parameters that are required for model building i.e. validation threshold and learning rate. In our experimental environment, 20 and 0.3 value is set for the threshold and learning rate respectively.

$$
a=\text { (attribs }+ \text { classes) } / 2
$$

The polynomial kernel was used by SVM as building model kernel and the it was based on the Eq. 2. The additional tuning parameter is tolerance which was set to 0.001 and used as a stopping criteria for SVM.

$$
K(x, y)=(<x, y>+1)^{p}
$$

The RandomForest was utilized with the default setting that includes the setting of the depth of the tree and feature's number. The Eq. 3 was used to find the number of feature used in the model. To avoid the excessive computational processing, only two iteration model was used. However, to get the accurate model, the depth of tree was set to infinity.

$$
f=\operatorname{int}\left(\log _{2}(\# \text { predictors })+1\right)
$$

\section{Performance Evaluation Matrices}

The community accepted evaluation models were used in the experiment. However, due to numeric dependant variable, the all those techniques that uses confusion matrix are not 
applicable here. Therefore, Root Mean Squared Error (RMSE), Mean Absolute Error (MAE), Relative Absolute Error (RAE), and Relative Squared Error (RSE). The 10-fold cross validation model was used for evaluation and all measures presented in the result section are average of the 10 folds.

\section{1) Root Mean Squared Error}

If the model error is calculated using single unit, then RMSE is used for validation of the model. The lower the error rate, the better model. Eq. 4 is used to find the RMSE.

$$
\text { RMSE }=\sqrt{\frac{\sum_{i=1}^{n}\left(p_{i}-a_{i}\right)^{2}}{2}}
$$

\section{2) Mean Absolute Error}

The MAE is also applicable in the scenarios where the single unit is used for measure the error of the model. MAE is similar in to RSME in magnitude but smaller in size. Eq. 5 is used

$$
\text { MAE }=\frac{\sum_{i=1}^{n}\left|p_{i}-a_{i}\right|}{n}
$$

\section{3) Relative Absolute Error}

In some situations, where different models use different units for find error, the RAE is used to compare the models. The Eq. 6 is used to calculate the RAE.

$$
R A E=\frac{\sum_{i=1}^{n}\left|p_{i}-a_{i}\right|}{\sum_{i=1}^{n}\left|\bar{a}_{i}-a_{i}\right|}
$$

Table 1: Data sources and variable description

\begin{tabular}{|l|l|l|}
\hline Variable & \multicolumn{1}{|c|}{ Description } & \multicolumn{1}{c|}{ Source } \\
\hline $\begin{array}{l}\text { Nominal } \\
\text { Exchange } \\
\text { rate }\end{array}$ & $\begin{array}{l}\text { MYR/USD } \\
\text { (Direct Quote) }\end{array}$ & $\begin{array}{l}\text { Department of Statistics } \\
\text { Malaysia (DOSM) }\end{array}$ \\
\hline Crude Oil & $\begin{array}{l}\text { Crude } \\
\text { Petroleum } \\
\text { (USD/bbl) }\end{array}$ & $\begin{array}{l}\text { Organization of the } \\
\text { Petroleum Exporting } \\
\text { Countries (OPEC) }\end{array}$ \\
\hline $\begin{array}{l}\text { Bid-Ask } \\
\text { Spread }\end{array}$ & $\begin{array}{l}\text { Forex Bid/Ask } \\
\text { Middle rate }\end{array}$ & $\begin{array}{l}\text { Bank Negara Malaysia } \\
\text { (BNM) }\end{array}$ \\
\hline Palm Oil & $\begin{array}{l}\text { Daily Palm oil } \\
\text { (RM/TONNE }\end{array}$ & $\begin{array}{l}\text { Malaysian Palm Oil Board } \\
\text { (MPOB) }\end{array}$ \\
\hline $\begin{array}{l}\text { Rubber } \\
\text { Price }\end{array}$ & $\begin{array}{l}\text { Closing Prices } \\
\text { (NR/Latex) }\end{array}$ & $\begin{array}{l}\text { Malaysian Rubber Export } \\
\text { Promotion Council } \\
\text { (MREPC) }\end{array}$ \\
\hline
\end{tabular}

\section{4) MEAN SQUARED ERROR}

Like the RMSE, The MSE is a measure of the quality of an estimator-it is always non-negative, and values closer to zero are better. It is a risk function, corresponding to the expected value of the squared error loss or quadratic loss. The MSE is shown in eq. 7

$$
M S E=\frac{1}{n} \sum_{i=1}^{n}\left(\hat{Y}_{i}-Y_{i}\right)
$$

\section{RESULT AND DISCUSSION}

The 10-fold cross validation is used to build and evaluate the model. The final model was then used to predict the 10 days in advance. The results were then compared with the actual values. The same procedures were repeated for SVM, NN, and RF. Fig. 1 shows the performance of the SVM Model. It shows the results of the 10 -fold cross validation for all instances. The results were presented with the $95 \%$ confidence level. The graph shows that the SVM result in the 10 -fold cross validation is following the same pattern as the actual values. However, this model is missing the abnormal fluctuation during its prediction.

Table 3 presented the future prediction of the model for the next 10 days. The date was taken from the dataset where the actual values are presented. The average MAE is 0.029 , RAE is 112.69, RMSE 0.04, and MSE is 0.002 .

Fig. 2 represent the results of the NN model for 10 -fold cross validation. The results show that the predicted values are comparatively different than the SVM model. The predicted values are smaller when the actual values are small and higher with the large actual values. The same fluctuation is reflected when the model was used to predict the future values.

Table 4 shows the result for the future values which were not part of the model building dataset. The mean absolute error is 0.035 , the RAE is 132.76 , the RMSE is 0.046 , and the MSE is 0.002. These results are comparative worse than the SVM. Further analysis can be used to change the internal setting of the NN to check the effect of the deep NN.

The Fig. 3 shows the results of the RF. The graph visually shows that the actual and the predicted values are nearly same. The reason of relatively near prediction is the random behavior of the random forest where it chooses the node randomly with the minimum possible.

Table 5 shows that the RF predicted the future values where the MAE is 0.019 , RAE is 74.02, RMSE is 0.026, and MSE is 0.001 .

The initial experiments and results showed the dominancy of the RandomForest over SVM and ANN. The randomForest is using random behavior and the Exchange rate also possess random nature. This is the reason that RandomForest outperformed the other two techniques. These findings are in-line with those presented in [33] who used the RandomForest for the commodity prices.

Further investigation of the randomforest revealed its comparative slow performance on the testing data than the training data. Therefore, the large size of training data will further improve the performance of the model on the testing data. When the test time is compared with the testing accuracy, then the small increase in the computational processing is acceptable in the real data.

\section{CONCLUSION AND FUTURE WORK}

The experiments revealed interesting facts about the prediction of the exchange rate using machine learning. It showed that the random nature of the RandomForest make it more suitable for the predicting the exchange rate with random behavior. This is the key reason of the better performance of the

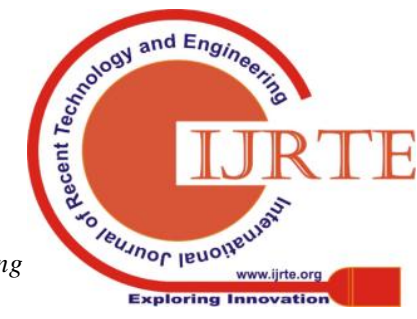


RandomForest over ANN and SVM. Thus, these experiments also support the random walk theory of the Meese and Rogoff. It is also highlighted that the larger dataset for the purpose of training the model can positively improve the prediction of exchange rate. Similarly, the high level frequency will enable the model to predict the dependent variable at more detail level and with comparatively high accuracy. Furthermore, the data cleansing technique can help to deal with the missing values which is common in the financial data.
There are a number of possibilities to further extend the current work. One direction is to study the working of RandomForest over a comprehensive dataset to analyse the factors of its improved performance. The model can also me enriched with other dependent variables as the current model only used the commodity price. The macroeconomic and microstructure are other key driving factors that my impact the exchange rate.

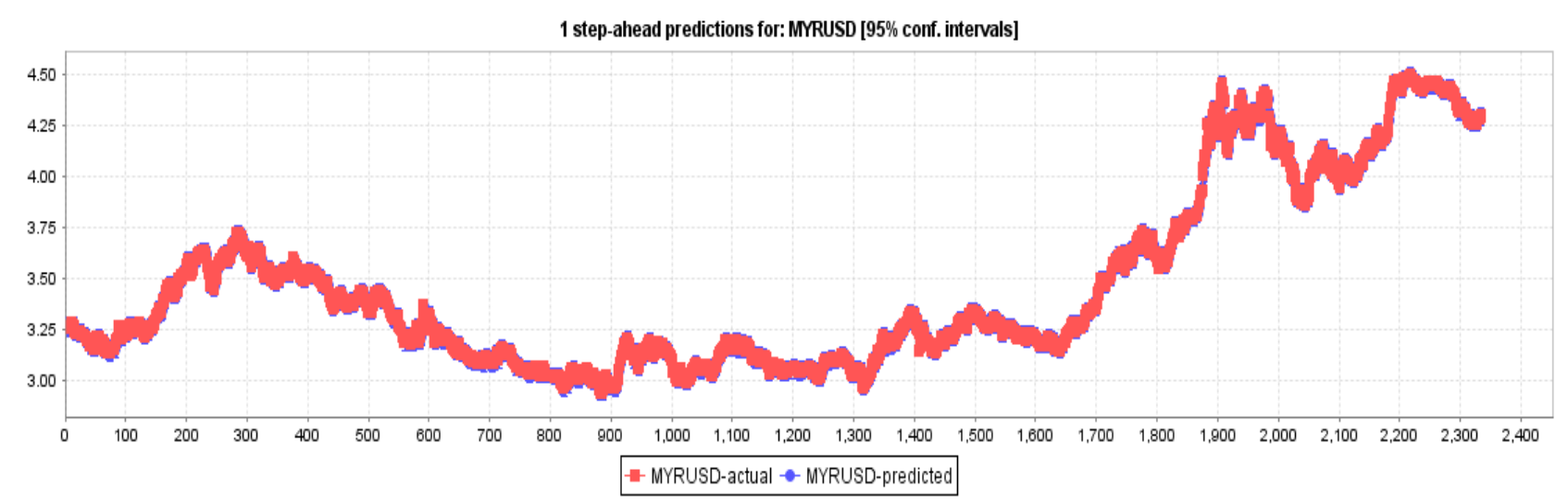

Fig. 1: Comparison of the actual and predicted value for SVM

Table 2: The evaluation of the future values based on the SVM model build on data from Jan 2008 - June 2017 (Prediction dates are from 3rd July 2017 to 14th July 2017)

\begin{tabular}{|c|c|c|c|c|c|c|c|c|c|c|}
\hline & 03-07 & 04-07 & 05-07 & 06-07 & 07-07 & 10-07 & 11-07 & 12-07 & 13-07 & 14-07 \\
\hline MAE & 0.01 & 0.02 & 0.02 & 0.03 & 0.03 & 0.03 & 0.03 & 0.04 & 0.04 & 0.04 \\
\hline RAE & 99.48 & 144.46 & 123.78 & 115.01 & 110.42 & 109.65 & 107.80 & 106.19 & 105.68 & 104.47 \\
\hline RMSE & 0.02 & 0.03 & 0.03 & 0.04 & 0.04 & 0.04 & 0.05 & 0.05 & 0.05 & 0.06 \\
\hline RSE & 0.00 & 0.00 & 0.00 & 0.00 & 0.00 & 0.00 & 0.00 & 0.00 & 0.00 & 0.00 \\
\hline
\end{tabular}

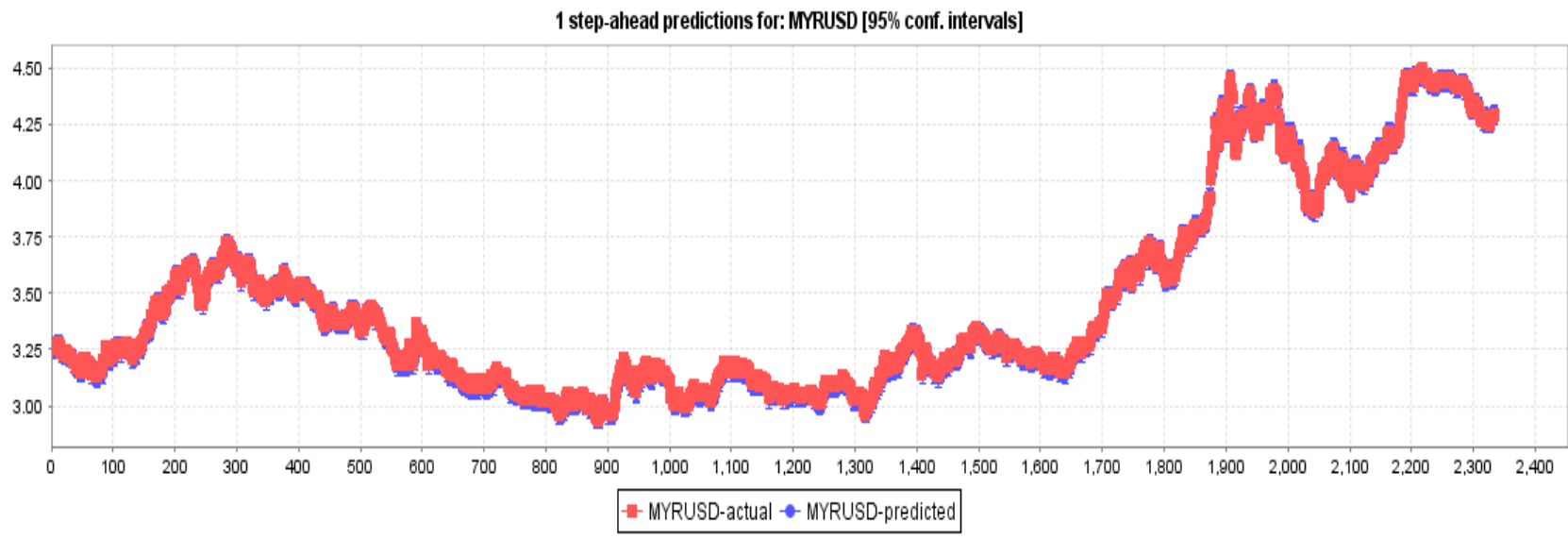

Fig. 2: Comparison of the actual and predicted value for NN

Table 3: The evaluation of the future values based on the NN model build on data from Jan 2008 - June 2017

\begin{tabular}{|c|c|c|c|c|c|c|c|c|c|c|}
\hline & 03-07 & 04-07 & 05-07 & 06-07 & 07-07 & 10-07 & 11-07 & 12-07 & 13-07 & 14-07 \\
\hline MAE & 0.01 & 0.02 & 0.02 & 0.03 & 0.03 & 0.04 & 0.04 & 0.05 & 0.05 & 0.05 \\
\hline RAE & 104.45 & 156.27 & 137.50 & 131.49 & 130.62 & 131.93 & 131.95 & 132.95 & 134.84 & 135.68 \\
\hline RMSE & 0.02 & 0.03 & 0.03 & 0.04 & 0.04 & 0.05 & 0.05 & 0.06 & 0.07 & 0.07 \\
\hline MSE & 0.00 & 0.00 & 0.00 & 0.00 & 0.00 & 0.00 & 0.00 & 0.00 & 0.00 & 0.00 \\
\hline
\end{tabular}




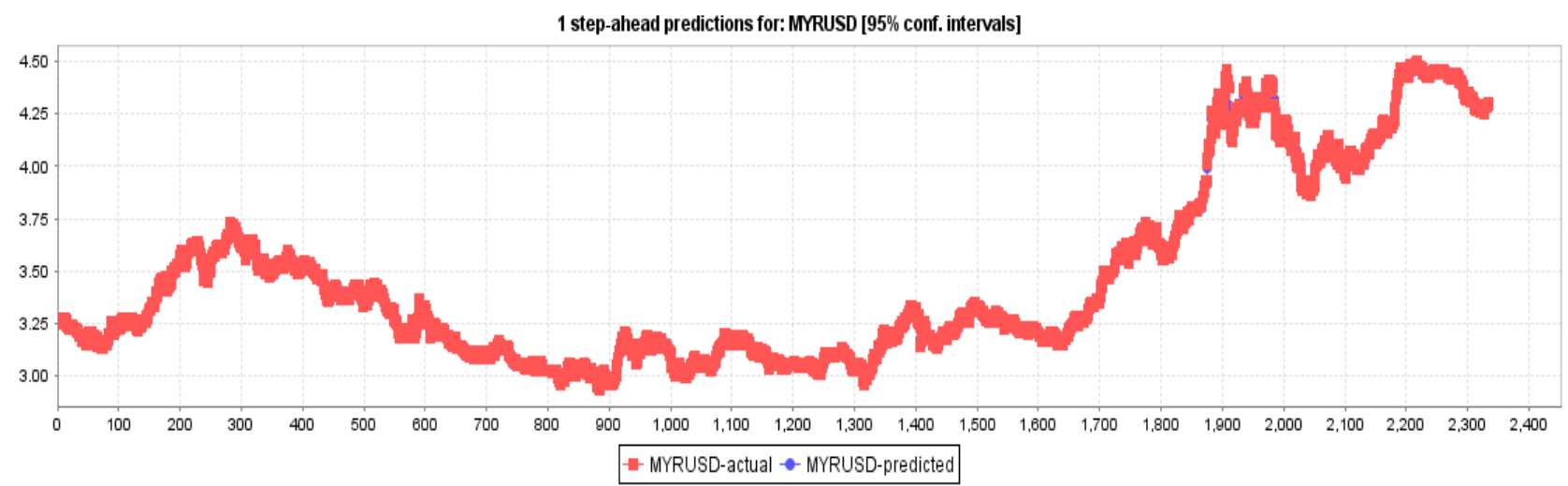

Fig. 3: Comparison of the actual and predicted value for RF

Table 4: The evaluation of the future values based on the RF model build on data from Jan 2008 - June 2017

\begin{tabular}{|c|c|c|c|c|c|c|c|c|c|c|}
\hline & 03-07 & 04-07 & 05-07 & 06-07 & 07-07 & 10-07 & 11-07 & 12-07 & 13-07 & 14-07 \\
\hline MAE & 0.008 & 0.011 & 0.014 & 0.016 & 0.018 & 0.021 & 0.023 & 0.024 & 0.026 & 0.028 \\
\hline RAE & 67.878 & 92.206 & 78.562 & 73.467 & 71.968 & 72.363 & 71.689 & 71.260 & 70.713 & 70.098 \\
\hline RMSE & 0.011 & 0.015 & 0.019 & 0.023 & 0.026 & 0.029 & 0.032 & 0.035 & 0.037 & 0.039 \\
\hline MSE & 0.000 & 0.000 & 0.000 & 0.001 & 0.001 & 0.001 & 0.001 & 0.001 & 0.001 & 0.002 \\
\hline
\end{tabular}

\section{REFERENCES}

[1] R. A. Meese and K. Rogoff, "Empirical exchange rate models of the seventies: Do they fit out of sample?," Journal of international economics, vol. 14, no. 1-2, pp. 3-24, 1983.

[2] R. A. Meese and A. K. Rose, "An empirical assessment of non-linearities in models of exchange rate determination," The Review of Economic Studies, vol. 58, no. 3, pp. 603-619, 1991.

[3] M. D. Evans and R. K. Lyons, "Order flow and exchange rate dynamics," Journal of political economy, vol. 110, no. 1, pp. 170-180, 2002.

[4] I. Mačerinskienè and A. Balčiūnas, "eXChange rate foreCasting With information floW approaCh," Business: Theory and Practice, vol. 17, p. 109, 2016.

[5] C. L. Osler, "Foreign exchange microstructure," Encyclopedia of complexity and system science, 2008.

[6] H. Chen, L. Liu, Y. Wang, and Y. Zhu, "Oil price shocks and U.S. dollar exchange rates," Energy, vol. 112, pp. 1036-1048, 2016.

[7] E. Kohlscheen, F. H. Avalos, and A. Schrimpf, "When the walk is not random: commodity prices and exchange rates," 2016.

[8] D. Ferraro, K. Rogoff, and B. Rossi, "Can oil prices forecast exchange rates? An empirical analysis of the relationship between commodity prices and exchange rates," Journal of International Money and Finance, vol. 54, pp. 116-141, 2015.

[9] E. Kohlscheen, "Long-Run Determinants Of The Brazilian Real: A Closer Look At Commodities," International Journal of Finance \& Economics, vol. 19, no. 4, pp. 239-250, 2014.

[10] H. Öğüt, M. M. Doğanay, N. B. Ceylan, and R. Aktaş, "Predicting Bank Financial Strength Ratings in an Emerging Economy: The Case of Turkey," 2012.

[11] E. López-Rubio and R. M. Luque-Baena, "Stochastic approximation for background modelling," Computer Vision and Image Understanding, vol. 115 , no. 6 , pp. 735-749, 2011.

[12] V. Plakandaras, T. Papadimitriou, and P. Gogas, "Forecasting daily and monthly exchange rates with machine learning techniques," Journal of Forecasting, vol. 34, no. 7, pp. 560-573, 2015.

[13] B. Rossi, "Exchange rate predictability," Journal of economic literature, vol. 51, no. 4, pp. 1063-1119, 2013.

[14] M. D. Chinn and M. J. Moore, "Order flow and the monetary model of exchange rates: Evidence from a novel data set," Journal of Money, Credit and Banking, vol. 43, no. 8, pp. 1599-1624, 2011.

[15] B. Rossi, T. Sekhposyan, and M. Soupre, "Understanding the sources of macroeconomic uncertainty," 2016.

[16] A. Paukšte and A. Raudys, "Intraday forex bid/ask spread patterns-Analysis and forecasting," in 2013 IEEE Conference on Computational Intelligence for Financial Engineering \& Economics (CIFEr), 2013, pp. 118-121: IEEE.

[17] H. Demsetz, "The cost of transacting," The quarterly journal of economics, vol. 82, no. 1, pp. 33-53, 1968.

[18] W. Bagehot, "The only game in town," Financial Analysts Journal, vol. 27, no. 2, pp. 12-14, 1971.
[19] A. Barnea and D. E. Logue, "The effect of risk on the market maker's spread," Financial Analysts Journal, vol. 31, no. 6, pp. 45-49, 1975.

[20] Y.-W. Cheung and C. Y.-P. Wong, "A survey of market practitioners' views on exchange rate dynamics," Journal of International Economics, vol. 51, no. 2, pp. 401-419, 2000.

[21] S. Chen, C.-C. Chien, and M.-J. Chang, "Order flow, bid-ask spread and trading density in foreign exchange markets," Journal of Banking \& Finance, vol. 36, no. 2, pp. 597-612, 2012.

[22] L. Katusiime, A. Shamsuddin, and F. W. Agbola, "Macroeconomic and market microstructure modelling of Ugandan exchange rate," Economic Modelling, vol. 45, pp. 175-186, 2015.

[23] T. M. Znaczko, "Forecasting Foreign Exchange Rates," 2013.

[24] C. K. Wambugu, "A Study of the Relationship Between Oil Prices, Exchange Rates and Maize Prices in Kenya," School of Business, University of Nairobi, 2012.

[25] A. Harri, L. Nalley, and D. Hudson, "The relationship between oil, exchange rates, and commodity prices," Journal of Agricultural and Applied Economics, vol. 41, no. 2, pp. 501-510, 2009.

[26] T. Koranchelian, The equilibrium real exchange rate in a commodity exporting country: Algeria's Experience (no. 5-135). International Monetary Fund, 2005.

[27] M. J. Zalduendo, Determinants of Venezuela's equilibrium real exchange rate (no. 6-74). International Monetary Fund, 2006.

[28] R. A. Lizardo and A. V. Mollick, "Oil price fluctuations and US dollar exchange rates," Energy Economics, vol. 32, no. 2, pp. 399-408, 2010.

[29] Q. F. Akram, "Oil prices and exchange rates: Norwegian evidence," The Econometrics Journal, vol. 7, no. 2, pp. 476-504, 2004.

[30] M. Hussain, G. F. Zebende, U. Bashir, and D. Donghong, "Oil price and exchange rate co-movements in Asian countries: Detrended cross-correlation approach," Physica A: Statistical Mechanics and its Applications, vol. 465, pp. 338-346, 2017.

[31] H. Aprina, "The Impact of Crude Palm Oil Price on Rupiah's Rate," Buletin Ekonomi Moneter dan Perbankan, vol. 16, no. 4, pp. 295-314, 2014.

[32] A. Shri Dewi, A. Ali, and M. Alias, "Impact of biodiesel blend mandate (B10) on the Malaysian palm oil industry," Jurnal Ekonomi Malaysia, vol. 48, no. 2, pp. 29-40, 2014.

[33] S. Ramakrishnan, S. Butt, M. A. Chohan, and H. Ahmad, Forecasting Malaysian exchange rate using machine learning techniques based on commodities prices. 2017, pp. 1-5.

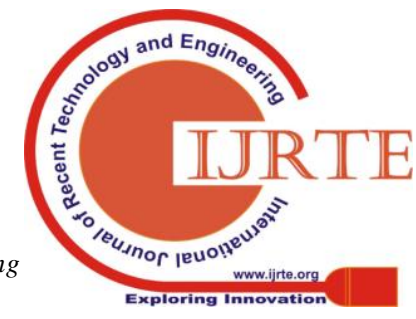




\section{AUTHORS PROFILE}

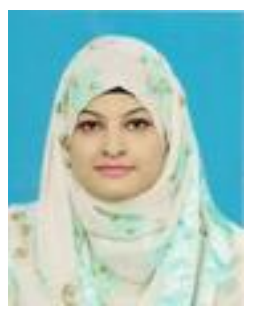

Mrs. Shamaila Butt is a Ph.D. candidate at Universiti Teknologi Malaysia, Malaysia. Shamaila earned her MS in Finance in 2013 from COMSATS University Islamabad, Pakistan. She worked as a lecturer at University of Wah, Pakistan. She has published a number of research articles in the International reputed journals and conference. Her research expertise are financial economics and financial econometrics.

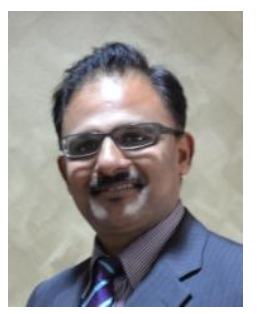

Dr. Suresh Ramakrishnan is a Deputy Dean (Research, Innovation, Development \& Alumni) and an Associate Professor of Finance at Azman Hashim International Business School, Universiti Teknologi Malaysia, Malaysia. Suresh received his Ph.D. in Finance from the Deakin University Australia and held teaching and administrative positions at Universiti Teknologi Malaysia, Malaysia. He has published a number of research articles in the International reputed journals and conference. His research interests are in the area of corporate finance, behavioral finance and corporate social responsibility.

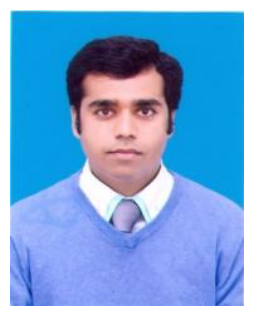

Muhammad Ali Chohan is a $\mathrm{PhD}$ candidate at Universiti Teknologi Malaysia, Malaysia. Chohan received his MBA finance from International Islamic University, Pakistan and BBA Finance from Bahria University, Pakistan. Ali worked as a visiting faculty lecturer at University of Sargodha, Pakistan. His research interests are in the area of corporate finance.

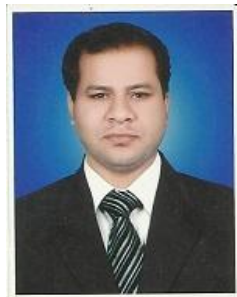

Suresh Kumar Punshi is a PhD candidate at Universiti Sains Malaysia, Malaysia. Suresh received his MA Economics from Shah Abdul Latif University Khairpur Pakistan and MBA Finance and Marketing from Institute of Business Administration Karachi, Pakistan Suresh is an experienced, academic and practical oriented business professional with over 10 years of expertise in the areas of Finance, Trading, Fund Management and Academics. 